\title{
25. COMMISSION DE PHOTOMETRIE STELLAIRE
}

Président: R. H. Stoy.

Membres: MM. Argyle, Baum, W. Becker, Behr, Butler, Cousins, de Kort, Dessy, Dufay, Eggen, Fracastoro, Greaves $\nmid$, Haffner, J. S. Hall, Harris, Heckmann, Hertzsprung, Hiltner, A. R. Hogg, Holmberg, Hunter, Irwin, H. L. Johnson, Keller, I. R. King, Kostylev, Kron, MacRae, Malmquist, Masani, Mees, P. Muller, A. B. Muller, Nikonov, Ninger-Kosibowa, Oosterhoff, Pettit, Rahman, Ramberg, Redman, Rybka, Schilt, H. Schmidt, Seares, Sharonov, Stebbins, Strohmeier, Tsesevich, Vanderlinden, van Rhijn, Velghe, Wallenquist, Weaver, Wesselink, Whitford, Zinner, Zonn.

\section{5a. SOUS-COMMISSION DES MAGNITUDES ÉTALON}

Président: W. Becker.

Membres: MM. Baum, Cousins, H. L. Johnson, Kron, Oosterhoff, Redman, Rybka, Stoy, Tsesevich, Vyssotsky, Wallenquist, Weaver, Whitford, Woolley.

\section{5b. SOUS-COMMISSION DE LA QUALITÉ DES IMAGES}

Président: J. S. Hall.

Membres: Butler, Hewish, Keller, Redman, Rösch, A. G. Wilson, Zwicky.

Once again the principal business of Commission 25 will be to consider the report of its Sub-Commission on Standard Magnitudes and to decide how far it endorses the proposals made therein. It seems only necessary to supplement Professor Becker's comprehensive report by a brief review of the general background against which any decisions or recommendations made by the Commission as a whole must be made.

Commission 25 is only indirectly concerned with spectrophotometry and with the photometry of double stars, variable stars, star clusters, nebulae, etc., which come within the province of other commissions. Its primary function is to provide a framework for the co-ordination of the observations of magnitude and colour which are made in connexion with a large variety of astronomical and astrophysical problems. Just what is observed in any particular case will depend on the precise information being sought and the equipment available but it is clearly an advantage if the observational results can be presented in some standard form so that observations made for the solution of one problem can be easily utilized for solving another. Any recommendations made by the Commission must therefore have as wide an application as possible and must be convenient in practice, or they will be ignored. As Prof. Greaves remarked in his last report:

When it comes to the operation of observing programmes a commission of the I.A.U. is a consultative and not a legislative body. It can recommend procedure, but individual astronomers can adopt any course they please. Generally speaking, I.A.U. commissions have been careful not to make recommendations on observational procedure unless it has become apparent that workers in the relevant field are prepared to accept them.

During the past three years the well-developed and accurate techniques of two- and three-colour photometry based on the use of photomultipliers with Sb-Cs cathodes have been extensively applied, especially to stars of early spectral type, to stars in clusters and to nearby stars, and have led to many important astrophysical results particularly in relation to theories concerned with the age and development of the stars. The principal developments in this type of photometry have been in the direction of extending the observations to very faint stars by means of pulse counting [r] and integrating devices [2]. Kron reports using ordinary d.c. constant deflection methods in conjunction with a 


\section{COMMISSION 25}

Lallemand nineteen-stage multiplier on the 36 -inch Crossley Reflector to measure to magnitude 20 with useful precision in about $15 \min [3]$. Baum reports on promising experiments with the new multi-alkali surfaces described by Morton at the Dublin meeting, but these cells are still being developed and are not likely to be available for general use in the near future.

In photographic photometry there has been a fairly steady output of photographic and photovisual magnitudes observed by more or less conventional methods. Development work has been mainly concentrated on harnessing the immense potentialities of the Schmidt camera to photometry. The technique of doing so is not yet fully worked out. It appears that the Schmidt will be most useful in crowded fields as a mass production method of interpolating between a number of previously known magnitudes in the field being observed. Experience has shown that meticulous attention must be paid to detail if reliable results are to be obtained. The magnitude obtained for a star from an in-focus image, especially when an iris-diaphragm photometer is used, depends rather critically on the structure of this image as it is formed by the combination of telescope, seeing and photographic emulsion. This dependence is of much greater practical consequence with a Schmidt telescope than with a conventional refractor, since the images are smaller and sharper, and the relatively small focal ratio makes them very sensitive to any maladjustment of the telescope. For this reason it is possible that it will not prove practicable to use Schmidts for transferring magnitude sequences from a standard field to a field in which magnitudes are to be determined, as can be done quite successfully with small photographic refractors. Schmidt telescopes can be used for multi-colour photometry and, while there is yet no general agreement on which colours are best for general observation, the $R, G, U$ colours, chosen by Becker on account of their astrophysical significance, are becoming increasingly popular.

Both photographic and photo-electric work in the red and infra-red have been continued, but neither seems to have developed with quite the vigour that the intrinsic interest and potential usefulness of the results seems to warrant. A red-sensitive photomultiplier of Soviet make has been successfully applied to stellar photometry by Prokofieva at the Crimean Astrophysical Observatory. Baum reports observations of faint objects in the red and infra-red made at the Mount Wilson and Palomar Observatories using either sixteen-stage infra-red-sensitive photo-multipliers supplied by the Farnsworth Electronics Company or an infra-red-sensitive photo-multiplier provided by Lallemand.

The six-colour photometry of Stebbins, Whitford and Kron has now been extended to 409 stars and the Sun [4] and provides excellent material from which the suitability of the various colours for general photometric purposes may be judged and also for interpreting the physical meaning of the wide-band photometries in normal use. Similarly useful in this connexion are the spectro-photometric observations that have been made by Whitford and Code and the experimental monochromatic magnitude work being carried out at Cambridge and elsewhere. Kron is making six-colour observations of super-giant stars in the hope of being able to derive their intrinsic colours and of using these to determine the reddening of classical Cepheids. Baum has used multi-colour photometry for measuring red-shifts of remote galaxies [5].

The question of which wave-length ranges should be used for magnitude and colour observations deserves more attention. In the past these wave-length ranges have been dictated by the means available rather than by the problem to be solved. Now that observational limitations are being increasingly removed, the choice of wave-lengths can be made more deliberately. In this connexion King has urged that thought should precede observation. He says

More attention should be paid to semi-theoretical discussions of relations between magnitude systems. The practice in the past has been to make the observations first and then to consider their meaning. The shortcomings of various magnitude systems have been discovered by bitter experience rather than foreseen, and the productivity of photometric 


\section{PHOTOMETRIE STELLAIRE}

observations has suffered. The value of series expansions, such as I have used, is limited; but the ready availability of high-speed electronic computers makes it possible to do large numbers of accurate numerical integrations instead.

Whitford has also commented on the need for a deliberate choice of the most useful wave-length bands for magnitude systems. He remarks

H. L. Johnson has emphasized that rejection of wave-lengths shortward of $3800 \AA$ gives a more unique blue-violet magnitude. It may turn out, I think, that the concentration of lines and bands in the violet region of late-type stars, and in the spectra of galaxies, will make this region less useful than the traditional visual region or perhaps a region in the red or infra-red. Standardization of these new photometric systems in the red or infra-red might properly be a subject for the Commission to consider.

Another question that deserves careful attention is the form in which the results of multi-colour photometry should be expressed. Before the Dublin Meeting, Redman expressed his fear that the continued introduction of new magnitude systems would lead to confusion and urged that efforts should be directed towards producing a system of parameters to describe stellar radiation, closely connected with the units of physics and not subject to change with the introduction of new observing techniques. The following series of parameters which do not introduce too great a break with the past may serve as a basis for discussion:

(I) a 'monochromatic' magnitude at a wave-length corresponding to the present $V$ magnitude to define the brightness of the star;

(2) the 'gradient' at this wave-length to define its 'colour' temperature and giving information more or less equivalent to the present $B-V$ or $P-V$ colours;

(3) a parameter, or parameters, measuring the departure of the actual stellar radiation from the assumed black-body distribution in certain specified wave-length ranges, e.g. at the head of the Balmer series;

(4) a parameter indicating the degree of interstellar reddening.

\section{STANDARD MAGNITUDES}

The use of any form of standard magnitudes depends on the ability to transform observations from an observed to a standard system without an appreciable loss of accuracy. The conditions under which these reductions can be made are now fairly well understood [ 6$]$. For precise work, not only the colour of the star but also its luminosity class and the degree of interstellar reddening may have to be taken into account. If observations are made under approximately standard conditions, there should be no difficulty about reducing them to the standard system within \pm 0.01 magnitudes. If the observations have been made under conditions differing widely from the standard conditions, conversion from the observed to the standard system may still be possible but, if simple transformation formulae are used, there are likely to be discrepancies of several hundredths of a magnitude for individual stars. Such discrepancies, if carefully investigated, can give important information about the particular stars involved.

The recommendations about standard magnitude systems that were made by Commission 25 at Dublin were as follows:

(I) for standardizing two-colour photometry, observers should use either (a) a modification of the International $p g$, $p v$ system, or $(b)$ the $B, V$ system of Johnson and Morgan, or $(c)$ in the Southern Hemisphere, the I953 $S$ system;

(2) for standardizing three-colour photometry, observers should use the $U, B, V$ system of Johnson and Morgan.

An examination of the observations published during the past three years indicates that the $B, V$ and the $U, B, V$ systems are being increasingly used, particularly for photoelectric work. At present the most comprehensive and convenient exposition of this 


\section{COMMISSION 25}

system is that given by Harold L. Johnson in the Annales d'Astrophysique [7]. Filters which appear to yield magnitudes that can be easily reduced to the $U, B, V$ system are

for $U$ Corning 9863 or $2 \mathrm{~mm}$ Schott UG I or UG 2

for $B$ Corning $5030+2 \mathrm{~mm}$ Schott GG I3 or I mm Schott BG I2 + 2 (or 4 ) mm GGI3 for $V$ Corning 3384 or $2 \mathrm{~mm}$ Schott GG II or I mm Schott OG 4 or Omag 302.

An aluminized reflector is needed for the satisfactory reproduction of the $U$ magnitudes, but refractors or silvered mirrors will reproduce the $B, V$ system. For photo-electric work a cell having a Sb-Cs cathode can be used, while for photographic work an 'ordinary' emulsion like the ro3 $a \mathrm{O}$ can be used for $U$ and $B$ and an emulsion like the Kodak ro3 $a \mathrm{D}$ for $V$. The selection of stars provided by Johnson seems to be adequate for photo-electric work in the northern hemisphere but not for the southern hemisphere when work of the highest precision is contemplated. Insufficient stars are available and Cape observations which are, however, not yet definitive, indicate a small variation of zero-point with right ascension in the magnitudes of those stars that are accessible.

Although the International $p g, p v$ system and its modifications continue to be extensively used, especially for photographic work, there is still no unanimity about its definition. Some observers attempt to retain the original 1922 definition [8], some the extended polar observations of Seares, Ross and Joyner [9], some the interim definition of I952 [ro] and some modified versions of the rather limited Californian definition [ri]. The confusion lies mainly in defining the zero-point and colour characteristics of the photographic magnitudes. The $I P v$ and $V$ systems are supposed to be the same and, as far as can be judged from non-polar stars, this appears to be the case in practice. For the stars in the North Polar Sequence itself, however, there is a considerable variation in the visual magnitudes found by different observers.

The I953 $S$ system is defined by the magnitudes of 740 stars in the nine Harvard Standard E Regions at $-45^{\circ}$ which are given in Cape Mimeogram no. 3. Work aimed at improving this system continues steadily and Cape Mimeogram no. 5 which is shortly to be issued gives the best data available at present for stars brighter than magnitude $8.7 S P g$. $V, B-V, S^{\prime} P g, S P v, S^{\prime} C I$ and $(U-B)_{c}$ are given for each star. The I953 $S P g$ includes a certain amount of radiation to the violet of $3800 \AA$. The $S^{\prime} P g$ system represents an attempt to remove the effect of this radiation. $(U-B)_{c}$ represents an ultra-violetblue colour index as measured with a refractor or silvered reflector. It cannot be directly related to the Johnson and Morgan $U-B$, but it serves a similar purpose both in the comparison of magnitudes made with instruments of different blue sensitivities and in separating out the luminosity classes near $B-V=0$.

So far no official recommendations about standard systems for work in the red, infra-red, or in the $R, G, U$ wave-length regions have been made.

\section{The Sub-Commission's report}

The two most important points raised in the Sub-Commission's report are the provision of a uniform zero-point system and the question of atmospheric extinction. This latter question will probably be fully discussed at Moscow where there is to be a joint meeting between Commissions $12,13,25,27$ and 36 to consider the problem of 'Extinction in Astronomical Observations'.

As far as stellar photometry is concerned, there seem to be two usual procedures for dealing with atmospheric extinction. The first is to reduce all the observational results to outside the atmosphere and the second is to apply small differential corrections to take account of the difference in zenith distance between the stars being observed and the standard stars. For ordinary routine work both procedures lead essentially to the same result since the magnitudes and colours of the programme stars are found by interpolation between the assigned magnitudes and colours of the standard stars after the observations of the programme and standard stars have been made and reduced together under precisely the same conditions. Thus the way in which the effects of atmospheric 


\section{PHOTOMETRIE STELLAIRE}

extinction are eliminated from the observations is of minor importance except when the standard stars of a photometry are being compared in an absolute way with a calibrated terrestrial standard. The ideal procedure for routine work would be to be able to compare stars with nearby standards at the same altitude, since in many places the extinction is known to vary not only with time but also with azimuth. Such a procedure, however, is only practicable when there is a large selection of standard, or semi-standard, stars available all over the sky.

The demand made in the Sub-Commission's report for more zero-point stars may arise partly from a desire to realize this ideal or it may arise from the failure of the present official standard systems to be completely adequate in practice. It cannot be denied that many of the Johnson and Morgan standards for the $U, B, V$ system are too bright for 'comfortable' observing, while their distribution over the sky is far from ideal. On the other hand, many observers would find the IIth and izth magnitude stars suggested by Becker too faint and would prefer the range of magnitude suggested by the Stockholm Symposium. It is hoped that this question can be discussed at Moscow in a joint meeting with Commission 37 .

A modification of Rybka's suggestion of a general magnitude catalogue may provide a solution to the problem of providing an adequate number of zero-point stars all over the sky for future photo-electric work. A careful compilation of the data now available should yield a catalogue of several hundred stars which have been observed photoelectrically at two or more observatories and for which the magnitudes and colours can be given with a probable error not greatly exceeding \pm 0 mor. The resulting catalogue would provide a firm foundation for the more general magnitude catalogue visualized by Rybka. It would also help to resolve the small inconsistencies between the existing series of standard magnitudes.

\section{Identification charts}

The general reaction to Wesselink's suggestion that special charts of the Selected Areas be made to accompany the magnitudes given in the Mount Wilson Catalogue can be summed up by a quotation from Kron's reply

Maps of the Selected Areas would be welcome, but the labour required to map all of the stars in all the areas is not only very large, but probably unnecessary. Standards by the thousands are not needed; what we need are fewer standards of higher quality, well distributed for observation and check in both hemispheres. For the present, it seems to me that it would be sufficient to ask all workers setting up new standards in the Selected Areas to publish charts, and that in addition charts should be published for the stars in the Selected Areas observed by Stebbins, Whitford and Johnson, as these have already been published without charts.

Redman suggests that the Commission should request that all published magnitudes of sequences below the 9 th or Ioth magnitude should be accompanied by identifications on a suitable chart. He further points out that for the northern section of the sky, charts can be prepared fairly quickly from enlargements of the appropriate portions of the Palomar Atlas. MacRae has called attention to the process used for preparing charts from plates taken with the Cleveland Schmidt [12]. If the stars concerned are not too faint, effective charts can also be prepared by direct enlargement of plates taken with a short focus refractor.

\section{PROGRESS REPORTS}

It is not possible to summarize here all the photometric work that has been carried out in the past three years. All that can be attempted is to give a brief reference to some of the work that has been reported by the members of the Commission and not previously mentioned.

The following summary of stellar photometry in the U.S.S.R. is based on a report prepared by Nikonov. At the Crimean Astrophysical Observatory $V$ and $B-V$ magni- 


\section{COMMISSION 25}

tudes and colours have been determined photo-electrically for 234 nearby stars brighter than magnitude 10.3 [13]. Similar observations have been made at the Engelhardt Astronomical Observatory and reduced at the Sternberg Astronomical Institute in Moscow, but in this case the magnitude limit was $8 \cdot 4$ [14]. Other photo-electric work in progress at the Crimean Observatory includes the application of two-colour diagrams to the spectral classification of early-type stars and to the study of selective interstellar absorption within the Galaxy. At the Burakan Astrophysical Observatory photo-electric observations have been made of the brightness, colour and polarization of the stars in the two stellar associations Perseus II and Cepheus II [15]. Similar observations of other associations have been started at the Pulkovo Observatory.

Photographic methods and a new $70-\mathrm{cm}$ meniscus telescope are being used at the Abastumani Astrophysical Observatory to determine the $p g$ and $p v$ magnitudes of $\mathrm{O}-\mathrm{B} 2$ giants, of the later type super-giants and of $\mathrm{B}-\mathrm{A}$ main sequence stars in order to study the relation between the spatial distribution of particular types of stars and the general galactic structure. At the same observatory, colours and spectra are being observed for stars in certain areas of the Milky Way (at present the region of the Great Rift) according to the plan proposed by Parenago [r6]. Colours are also being observed for stars in a number of Kapteyn Selected Areas. At the Sternberg Institute $p g$ and $p v$ magnitudes have been determined for IIOO stars in the vicinity of $S$ Monocerotis and in the region of Orion's Belt. The Crimean Observatory has published a catalogue giving the $p g, p v$ magnitudes and spectral types of $575^{2}$ stars in a region of $7^{\circ} \times 7^{\circ}$ centred at $23^{\mathrm{h}} 25^{\mathrm{m}},+61^{\circ} \cdot 5^{\text {[1 }}$ ]. Similar catalogues with centres at $20^{\mathrm{h}} 04^{\mathrm{m}},+36^{\circ} ; \mathrm{I}^{\mathrm{h}}$ 10 $\mathrm{m},-15^{\circ} 0$; $2 \mathrm{I}^{\mathrm{h}} 24^{\mathrm{m}},+58^{\circ} 5$ and $20^{\mathrm{h}} \mathrm{I} 5^{\mathrm{m}},+42^{\circ} \cdot 7$ and containing more than $\mathrm{I} 2$ ooo stars are in press. Photographic and photovisual magnitudes for 18000 stars brighter than magnitude I3 in the regions $19^{\mathrm{h}}-20^{\mathrm{h}}, 0^{\circ}-+20^{\circ}$ and $4^{\mathrm{h}}-5^{\mathrm{h}},+5^{\circ}-+25^{\circ}$ are being observed at the Astronomical Observatory of the Ukrainian Academy of Sciences (Goloseevo) while photographic magnitudes of stars in the declination zone $+5^{\circ}$ to $+15^{\circ}$ are being determined at the Odessa Astronomical Observatory (Dragomiretzkaya). Atmospheric extinction has been intensively investigated at the Abastumani and Engelhardt observatories.

The 340/500/1375 mm Schmidt telescope of the Höher List observing station of the Bonn Observatory is to be used principally for photometry on the $R, G, U$ system. The first programmes will be concerned with setting up standard magnitude sequences in the North Polar Area and in Kapteyn Selected Areas 2, 4 and 6. The limiting magnitude will be about $I 5.5$ for $G$. The atmospheric extinction at Höher List is being investigated from three-colour photo-electric observations made during the period I953-57.

At the Cambridge Observatories the photometric work has been mainly experimental. A pulse-counting photometer has been used to investigate the properties of quasimonochromatic magnitudes for wave-length bands about $200 \AA$ wide sharply defined by means of a fairly simple spectrometer. It was found that such magnitudes could closely mimic the colour systems of $I P g, I P v, U$ and $B$ if an appropriate wave-length was chosen. The photometric properties of the Cambridge Schmidt telescope are also being critically investigated. Three-colour surveys on the $R, G, U$ system are being made in Kapteyn Selected Area 8 and in Praesepe. The dimensions of the instrument are $430 / 610 / 1600 \mathrm{~mm}$ and the limiting magnitude for $R, G, U$ photometry is about 16.5 for a 30 min exposure.

At the Canberra Observatory Bok is making photo-electric observations in Kapteyn Selected Areas I4I, I58, I93 and in the Large Magellanic Cloud where van Wijk's sequence and stars in Shapley's constellation III are being observed. He is also observing colours of B stars near Kapteyn Selected Area I93. Gascoigne has established $U, B, V$ sequences in NGC 6397 (to near magnitude I7), 47 Tucanae and $\omega$ Centauri. He plans to work on areas in the Large Magellanic Cloud. Hogg has made $U, B, V$ measures of 250 bright stars and is observing Harvard Sequence no. I in the Small Magellanic Cloud, as well as stars in NGC 330,4755 and IC 4725 . Rodgers has set up a $U, B, V$ sequence to magnitude 14.5 centered at $12^{\mathrm{h}} 42^{\mathrm{m}},-62^{\circ} 40^{\prime}$ (1950 $0^{\circ}$ ) and is observing $P, V$ magnitudes of I04 B stars in the Large Magellanic Cloud. 


\section{PHOTOMETRIE STELLAIRE}

At the Cape Observatory the photographic determination of $S P g$ and $S P v$ magnitudes for stars in the Cape Photographic Catalogue for $1950^{\circ}$ o has continued steadily and magnitudes and colours are now available for over 50 ooo stars [18]. Two-colour photoelectric observations of southern bright and nearby stars have been continued and threecolour observations of selected lists of stars have been commenced. Results, depending on a minimum of four observations per star, are available for 1350 stars in two colours and for 300 stars in three colours. During extended visits to South Africa, Irwin made threecolour observations of about I40 southern cepheids and Arp collected material for a population study of the Small Magellanic Cloud.

At Göttingen a photographic method of measuring the polarization of star light with polaroid and a calcite crystal has been developed and used to measure 325 stars in Kapteyn Selected Area 40 and in the region of the Pleiades. Magnitudes on the $R G U$ system are given for each star [19]. A differential photo-electric method for the measurement of stellar polarization has also been developed [20].

From the Royal Greenwich Observatory at Herstmonceux Eggen reports that all the observations he obtained at Lick and at Canberra have been published. The photometric work at the new Greenwich Observatory is to be concentrated on variable stars, nearby stars and visual binaries.

At the Praha Observatory, Perek has investigated the possibility of deriving blue and red magnitudes and colour indices from measurements of the prints of the Palomar Atlas. For satisfactory results it appears to be necessary to have accurate magnitudes in two colours for $(a)$ a sequence of stars reaching down to the limiting magnitude of the prints in a small area of each field, and $(b)$ several stars, which may be as bright as magnitude Io to $\mathrm{I}_{3}$, distributed all over the field.

At the Radcliffe Observatory, Wesselink has made three-colour photo-electric observations of faint B stars and of physical members of the Magellanic Clouds. He has set up a magnitude sequence near 47 Tucanae which he has also studied photometrically by means of direct photographs taken at the Newtonian focus of the 74-inch reflector. Thackeray and Wesselink have measured the polarization in the halo of $\eta$ Carinae.

Photometric work at the Rutherfurd Observatory has been mainly concentrated on population studies of the Magellanic Clouds and $\omega$ Centauri.

At the Uppsala Observatory red magnitudes are being measured with a $300 / 380 / 690 \mathrm{~mm}$ Schmidt camera. Results have been published for 466 stars brighter than magnitude I0.5 and north of $+86^{\circ}$ [2x]. A I3-inch refractor is being used to measure the photoelectric magnitudes and colours of about 220 early-type stars brighter than magnitude Io in the neighbourhood of the North Galactic Pole. The same instrument has been used to observe $165 \mathrm{~B}$ and A type stars in the dark and bright regions of Cepheus for an investigation of colour-excesses. It has also been used to provide standards in connexion with spectral-photometric investigations of selected Milky Way regions. Photo-electric observations of the differences in colour and magnitude between the components of wide double stars and stars with common proper motion have been made with a r6-inch Cassegrain reflector. Photographic photometry with refractors is being used for a threecolour study (64I0, 52 Io and $4250 \AA$ ) of about I500 stars brighter than magnitude I4 near M I03 for which proper motions have been determined.

At the Washburn Observatory the results for over 400 stars observed in South Africa by Code and Houck in I953 and I 954 are nearing completion. Most of the stars are of early type and some of them are as faint as the I8th visual magnitude. These are intended as standards for work in the Magellanic Clouds. The magnitude system is close to $U, B, V$ and correlations with that system will be provided.

Observations of early-type stars for $U, B, V$ photometry and inter-stellar polarization continue at the Yerkes Observatory. The results for I259 such stars have been published together with the corresponding spectral types [22]. Also published are catalogues giving the $U, B, V$ magnitudes and spectral types for $O$ stars [23] and for early type stars between galactic longitudes $338^{\circ}$ and $33^{\circ}$ [24]. 


\section{COMMISSION 25}

\section{AGENDA FOR THE MOSCOW MEETING}

The principal business will be the consideration of the report of the Sub-Commission on Standard Magnitudes. The question of atmospheric extinction will probably be discussed at a joint meeting of Commissions $12,13,25,27$ and 36 , and the possible need for additional zero-point stars and magnitude sequences along the Milky Way at a joint meeting with Commission 37. Other questions that might usefully be discussed are:

(I) The functions of the Commission and Sub-Commissions.

(2) The best procedure for measuring red and infra-red magnitudes and the adoption of a standard system for such measures.

(3) The provision of standards to define the $R, G, U$ system.

(4) The relationship between the standard systems and the best form, both practical and theoretical, in which the photometric observations can be expressed.

(5) The use of Schmidt telescopes for photometry.

(6) Recent improvements in photo-electric technique.

(7) Whether the wave-length bands now in use are the most suitable for astronomical observation.

(8) Monochromatic magnitudes and their uses.

(9) Multi-colour photometry and its possible applications.

(Io) The selection for intensive study of a suitable region for checking photometric equipment.

(II) The desirability of preparing a catalogue of standard magnitudes and also of a general catalogue of magnitudes.

(I2) The preparation of identification charts.

(I3) Polarization.

R. H. STOY

President of the Commission

\section{REFERENCES}

[I] Baum, W. A. Mount Wilson and Palomar Obs. Reprint I7I, 1955.

[2] Johnson, H. L. and Sandage, A. R. Ap. J. 124, 379, 1956.

[3] Kron, G. E. P.A.S.P. In press.

[4] Stebbins, J. and Kron, G. E. $A p . J .123,44^{\circ}$, I956; 126, 266, I957.

[5] Baum, W. A. Astr. J. 62, 6, I957.

[6] Harris, D. L., Johnson, H. L. and Morgan, W. W. Ap. J. 118, 92, 1953.

[7] Johnson, H. L. Ann. Astrophys. 18, 292, 1955.

[8] Seares, F. H. Trans. I.A.U. 1, 69, 1922.

[9] Seares, F. H., Ross, F. E. and Joyner, M. C. Mount Wilson Papers, 6, I94I.

[Io] Redman, R. O. Trans. I.A.U. 8, 375, I954.

[II] Johnson, H. L., Stebbins, J. and Whitford, A. E. Ap. J. 112, 469, $195^{\circ}$.

[12] Nassau, J. J. and MacRae, D. A. Ap. J. I10, 495, 1949.

[13] Nikonov, V. B., Nekrassova, S. V., Polosuchina, N. S., Rachkovsky, D. N. and Chuvaev, K. K. Publ. Crimean Obs. 17. 1957.

[14] Sharov, A. S. Dissertation. Moscow, 1955.

[15] Grigorian, K. A. Publ. Burakan Obs. 1957.

[I6] Parenago, P. P. Astr. J., Moscow, 33, no. 5, 1956.

[I7] Brodskaja, E. S. Publ. Crimean Obs. 14, 1955.

[18] Cape Annals, 17, I954; 18, I955; 19, 1955.

[19] Tripp, W. $Z . A p .41,84$, 1956; van den Bergh, S. $Z . A p .40,249$, 1956.

[20] Behr, A. Veröff. Univ. Sternw. Göttingen, no. II4, I956.

[21] Westerlund, B. Medd. Uppsala Obs. no. II3, 1955.

[22] Hiltner, W. A. $A p . J$. Supp. no. 24, 2, 389, 1956.

[23] Hiltner, W. A. and Johnson, H. L. Ap. J. 124, 367, 1956.

[24] Hiltner, W. A. and Iriarte, B. $A p . J .122,185,1955$. 


\section{PHOTOMETRIE STELLAIRE}

\section{5a. SOUS-COMMISSION DES MAGNITUDES ETALON}

Since I950 there has been a period of rapid development in photometry, both in the clarification of the basic concepts and in the drawing up of the necessary programmes to give them a more fruitful application. Sub-Commission $25 a$ has had to deal with the following questions:

I. The setting up of photometric scales;

2. The choice of standard fields;

3. The setting up of a photometric zero-point system;

4. The choice of suitable spectral domains for photometric systems;

5. The relationship between the different photometric systems.

The present position with regard to these questions may, perhaps, be summarized by the following general statements:

I. Setting up photometric systems has become mainly a task for photo-electric photometry. The number of photometric sequences is continually increasing, particularly by the measurement of star clusters.

2. Photometric sequences for the areas selected by the Sub-Commission are now available or will shortly be published (see Table, p. 378). References to other sequences in or near clusters will be found in the report of Commission 37 .

3. The question of a system of zero-point stars is a most urgent one, as has already been pointed out at the Meeting in Rome, in Dublin and at the 'Co-ordination of Galactic Research' Symposium held at Stockholm in I957. Unfortunately, the Sub-commission has not yet paid much attention to this question which should form one of the chief subjects for discussion at Moscow.

4. It is now generally accepted that in many cases a three-colour photometry gives considerably better results than two-colour photometry, especially if the third spectral region lies in the ultra-violet. The recommendation made by Commission 25 at Dublin that the $U, B, V$ system should be used for three-colour photometry has been generally followed. But it would be a misinterpretation of this recommendation to renounce further trials with other spectral regions (e.g. the $R, G, U$ system) which may prove more effective for some purposes such as the distinction between giants and dwarfs for the later spectral types which is important for stellar statistics. Such tests are in progress at Cambridge and Basle.

5. The relationship between the various photometric systems was discussed both at Rome and at Dublin. It is generally believed that various systems can be transformed into each other with a precision of about $\pm 0 \cdot 0$ I magnitude if suitable colour indices are available to eliminate the colour equation. It must be added, however, that such transformations are only of physical significance if the spectral regions of both systems only differ slightly from each other. If this is the case, a single-colour index will usually be sufficient to eliminate the colour equation. With certain problems a simple transformation of photometric systems may be misleading, e.g. when comparing colour-magnitude diagrams of clusters. Such problems can only be dealt with by measurements within the same system.

STANDARD SYSTEMS AND STANDARD AREAS

The table on p. 378 attempts to collect together the areas in which there are sequences suitable for the transfer of a photometric scale. It is not complete. The North Polar Area is not included.

\section{PHOTOMETRIC SEQUENCES}

The following paragraphs summarize briefly the reports of work in progress that have been received. 


\section{COMMISSION 25}

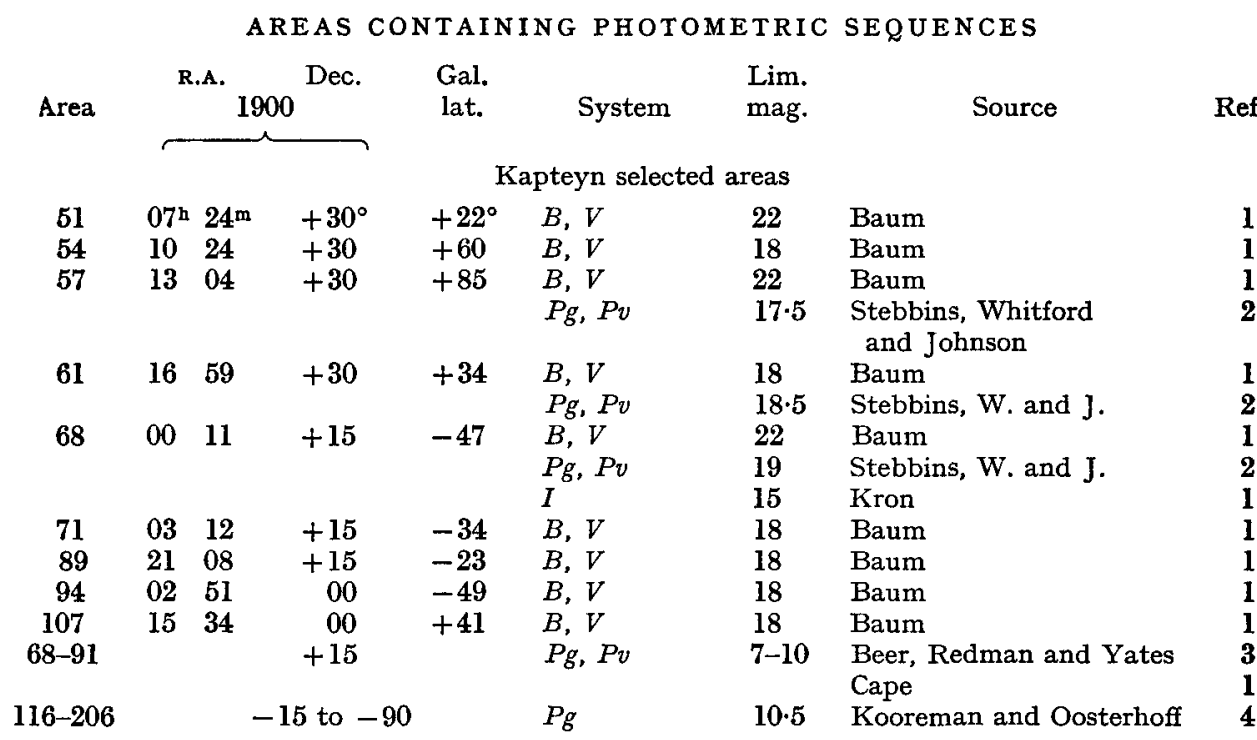

$\begin{array}{cccc}\text { C } 6 & 11 & 00 & +15 \\ \text { C } 8 & 15 & 00 & +15 \\ \text { C } 12 & 23 & 00 & +15 \\ \text { C 1-12 } & & & +15 \\ \text { E } 1-9 & & & -45\end{array}$

\begin{tabular}{lll}
\multicolumn{3}{r}{ Harvard standard regions } \\
+63 & $P, V, I$ & \\
+56 & $P, V, I$ & \\
-42 & $P, V, I$ & \\
& $B, V$ & 13 \\
& $(U), P g^{\prime}, P v$, & 12 \\
& $V, B-V$ & \\
& $P g, P v$ & 16
\end{tabular}

$\begin{array}{ll}\text { Kron } & \mathbf{1} \\ \text { Kron } & \mathbf{1} \\ \text { Kron } & \mathbf{1} \\ \text { Leander McCormick } & \mathbf{1} \\ \text { Cape } & \mathbf{5} \\ \text { Cape } & \mathbf{6}\end{array}$

\section{REFERENCES TO TABLE}

\section{[r] Unpublished.}

[3] Mem.R.A.S. 67, I, I954.

[5] Cape Mimeogram in course of preparation. $(U)$ refers to the ultra-violet light measured with a refractor and $P g^{\prime}$ to the photographic light measured through a GG I $_{3}$ filter.

[6] Cape Mimeogram no. 3, 1953 .

Baum (Mount Wilson and Palomar) reports that photo-electric sequences have been measured in the nine Kapteyn Selected Areas indicated in the Table. These are intended primarily for calibrating photographic transfers and an attempt has been made to distribute the stars in each sequence uniformly in magnitude. The observations were made in two colours and are reducible to the $B, V$ system. The zero-points and the colour system of the final data were based on stars in the North Polar Sequence. Altogether there are about 400 stars. The observations and reductions are complete and the material is being prepared for publication.

Cousins and Stoy (Cape) report that work on the Standard E Regions at $-45^{\circ}$ has been continued, particular attention being paid to the stars between magnitudes 7 and $\mathrm{I} 2$. It is believed that any one of the nine sequences will be found adequate for the standardization of photographic plates for scale, zero-point, colour equation and Purkinje effect to about magnitude 12.0 in the blue and yellow spectral regions and, with certain limitations, in the ultra-violet. The stars brighter than magnitude 8 have been observed in several series of independent observations and the individual blue and yellow magnitudes 


\section{PHOTOMETRIE STELLAIRE}

are of high precision. These stars should therefore be acceptable to photo-electric observers for fixing zero-points and colour equations and for use as extinction stars. A list of these stars has been prepared and will be available in mimeograph form in the near future.

Kooreman and Oosterhoff (Leiden) have determined photographic magnitudes for I5 000 stars brighter than magnitude I0.5 in the Southern Kapteyn Selected Areas. The scale was checked by photo-electric observations and particular attention was paid to securing a homogeneous zero-point. This work, which also concerns Commission 32 , is published in vol. XXI of the Annals of the Leiden Observatory.

Kron (Lick) reports that three-colour standards on the $P, V, I$ system have been set up in the Harvard Standard Regions C 6, C 8, C I2 and D ro, to which it is planned to add $\mathrm{C}_{4}$, $\mathrm{D} 2$ and D 6. The transfers were made from twenty-two stars in the North Polar Sequence. By using this many stars, and rejecting discordant stars, the Polar Sequence system can be accurately copied by photo-electric means. The blue magnitude, $P$, is ultra-violet-free, like the Johnson-Morgan $B$ magnitude, but is a closer approximation to the International photographic magnitude, $I P g$. At the request of $\mathrm{B}$. Westerlund infra-red magnitudes are being determined at Lick for thirteen stars in Kapteyn Selected Area no. 68. These have been chosen from the stars observed by Stebbins, Whitford and Johnson and go down to photographic magnitude $17 \cdot 0$ or about infra-red magnitude 15 . The infra-red system used is that set up by Kron and Smith. Kron also reports that some convenient standards for six-colour photometry are being set up in the declination belt $+15^{\circ}$ to $-15^{\circ}$.

Vyssotsky (Leander McCormick) reports work on all twelve Harvard Standard C Regions at $+15^{\circ}$. Stars between magnitudes 9.0 and Io.5 have been compared directly with the Polar Sequence in both photographic and photo-visual light to establish the zero-point in each region. Stars between magnitudes 6 and 13 have been observed photoelectrically in blue and yellow light.

Weaver (Leuschner) reports that short photo-electric sequences on the $B, V$ system have been set up in fourteen open clusters, namely, NGC 457, 752, I039, 681 1 , 687 I, 6940, 7092, $7160,7209,7243,7686,7789$, Mel 210, Tr 2. This work, which also concerned Commission 37 , has not yet been published.

\section{ZERO-POINT SYSTEMS}

In some of the sequences given in the Table particular care has been paid to the zeropoint, but, in general, there is a lack of a unified zero-point system. Rybka reports progress both at the Wroclaw and the Crimean observatories with the programme he outlined at the Rome and Dublin meetings, namely, the precise determination of $I P g$ and $I P v$ magnitudes for two stars of about magnitude 6 near each of the II5 northern Kapteyn Selected Areas, one of the stars being of type A and the other of type K. The purpose of this work is to secure uniformity of zero-point over the sky and to provide a network of stars suitable for obtaining the local instantaneous extinction.

It is clearly the task of Sub-commission $25 a$ to establish a unified zero-point system and to recommend that it be adopted for all future work. The essential properties that such a zero-point system for transfer purposes should have appear to be as follows:

I. The magnitudes should be in the $U, B, V$ system recommended by Commission 25 .

2. The system should be suitable for photo-electric and also for less precise photographic transfers.

3. The stars should lie in a narrow interval of apparent magnitude, bright enough for telescopes of medium size but not too bright for big ones.

4. The stars of every single zero-point region should not lie too close together for telescopes with a relatively short focal length, but not too far apart from each other for telescopes of relatively long focal length.

5. The stars should belong to a narrow spectral interval in order to be uninfluenced by small colour equations.

6. The stars should be of such a spectral type that small differences in the sensitivity function of the observational equipment do not have too pronounced an effect on the magnitudes. (This rules out A type stars because of the Balmer jump.) 


\section{COMMISSION 25}

7. The stars should belong to such an interval of spectral type that they can be found everywhere in the sky in sufficiently numerous groups.

These requirements might be met by the following proposal: A selection of five early G-dwarfs between magnitudes II and I 2 in each of thirty areas, IO' to $20^{\prime}$ in extent. The magnitudes should be determined accurately on the $U, B, V$ system. This proposal is intended to serve exclusively for the transfer of the zero-point; not for the detection and determination of colour equations or scale errors. It does not specify the distribution of the areas. Some of the areas given in the Table (p. 378) might form part of the proposed zero-point system, but it might be advisable to take advantage of the statistical density fluctuations to choose the stars by means of the spectral classification in the Kapteyn Selected Areas.

A different proposal was made by Haffner, Sandage and Walker at the I957 Symposium on 'Co-ordination of Galactic Research'. They suggested a series of regions in the declination zones $+45^{\circ}, 0^{\circ}$ and $-45^{\circ}$ in each of which accurate $U, B, V$ magnitudes should be measured for two white and two red stars, one of each pair being approximately of magnitude 8 and the other-of magnitude Io.

Commission 25 will have to discuss the whole question of a zero-point system at Moscow and, if at all possible, should issue a recommendation.

\section{STANDARD AREAS FOR THE COMPARISON OF SYSTEMS}

There is a much-felt need for the comparison of photometric systems, although one cannot deny that such comparisons quite often do not lead to any practical consequence. In the past, comparisons of systems have been carried out by means of stars which have been, more or less accidentally, measured on both systems. Open clusters have also been used for this purpose, though they are known to be quite unsuitable. Commission 25 should examine the question as to whether one or two Kapteyn Selected Areas should be specifically recommended for the comparison of photometric systems. In such an area, about fifty stars of all spectral types between magnitudes 9 and II should be measured on the $U, B$, $V$ system and also possibly on the six-colour photometry system. A representative number of these stars should also be observed spectro-photometrically in order to provide the means of finding immediately the position of the isophotal wave-length of any system. This would be a very welcome check on the values obtained in the laboratory which are quite often inaccurate and misleading.

\section{VARIA}

Weaver expresses the opinion that at the Moscow Meeting the duties and scope of Subcommission $25 a$ should be discussed and possibly redefined. The Sub-commission was set up several years ago when the needs and methods of photometry were significantly different from what they are at present.

Rybka reports that he is engaged on an examination of the systematic differences between the magnitudes given in Harvard Annals, 14, 23, 44 and 45 with the aim of reducing them to a uniform system. He urges that the very extensive observational material for stars brighter than magnitude 7.5 in the existing catalogues should be investigated for systematic errors and utilized to form a general catalogue of magnitudes and colours for the bright stars. Such a catalogue would contain mainly the stars that were unreddened by interstellar absorption and would thus define the normal colour indices of many stars. It would also be useful in keeping a uniform zero-point over the sky.

Rybka also suggests that the effects of atmospheric extinction should be carefully discussed and recommends that all photometric observations should be reduced to outside the atmosphere.

Cousins and Stoy recommend that attention be paid to the establishment of standards for red magnitudes and raise the question as to whether there is any need for standard stars in connexion with polarization studies.

W. BECKER

President of the Sub-Commission 


\section{5b. SOUS-COMMISSION DE LA QUALITE DES IMAGES}

\section{DEFINITIONS}

The title of Sub-commission $25 b$ was suggested by A. Danjon to include all types of changes in telescopic images produced by the Earth's atmosphere. The word seeing has been used for many years to describe changes in the size or position of images. Several authors have recently used the term scintillation to describe brightness changes alone. Although there have been exceptions to these usages, they are few, and the more common meanings should be followed if further confusion is to be avoided. Scintillation is identical in spelling and meaning in both French and English but seeing, unfortunately, has no French equivalent. Rösch suggests that agitation and étalement be used to describe the motion and spreading of images.

\section{SEEING}

Since the time of the Dublin meeting important progress has been made in furthering the development of means of combating poor seeing produced in the immediate vicinity of the telescope. Rösch [r] has been able to demonstrate a marked improvement in seeing when the tube of the telescope is ventilated.

Along somewhat similar lines Redman [2], Fellgett, Dewhirst, and Willstrop have made a study of local conditions around their new 36-inch reflector. They have installed a system which maintains a strong downward draft through the aperture of the dome and past the telescope and a similar flow down the telescope and over and around the mirror. When not in use the mirror and its cell are refrigerated so that the mirror is maintained at the air temperature predicted for the coming night. They have found that 'a necessary, but not sufficient, condition for good seeing with a reflector is that the mirror should not be warmer than the ambient air'. By use of these techniques image diameters of about $2 \mathrm{sec}$ of arc are average; previously they were often as large as $5 \mathrm{sec}$ of arc. The image size appears now to be controlled almost entirely by conditions outside the dome. Further comments on this matter have been published by W. H. Steavenson [3]. A related subject of great interest is that discussed in A. Couder's [4] paper on 'Thermal Distortions of Telescope Mirrors and Their Correction'.

Rösch [5] has developed a simple quantitative photo-electric method which is capable of measuring the scintillation, spreading and motion of the stellar image. Mikesell and Hall have been making similar experiments; an auxiliary arrangement has been constructed and will be attached to the Polaris monitor at the Flagstaff Station of the U.S. Naval Observatory so that the seeing can be automatically recorded on every clear night.

Zwicky [6] has continued his photographic study of trailed images and the Respighi bands.

The use of television techniques by Dewitt, Hardie and Seyfert [ 7$]$ to 'tranquillize' images of bright sources, such as planets, has met with considerable success on nights when the excursion of the image as a whole would normally prevent securing sharp images. Corrective voltages from two photo-cells are used to induce compensating currents in deflexion coils placed outside the envelope of an image orthicon. Corrections can be made as fast as $2000 / \mathrm{sec}$.

\section{OPTICAI SCINTILLATION}

A considerable amount of work on scintillation has been done. A major part of this work was carried on by the Ohio State Group under Keller's direction and is summarized in a very comprehensive final report by Keller, Protheroe, Barnhart and Galli [8]. This report also contains an extensive bibliography of recent work on the 'Effects of Atmospheric Turbulence on Image Behaviour'.

Rapid progress was made during the past three years in measuring the shadow pattern velocities and in identifying them with wind velocities at high levels. These progressed 


\section{COMMISSION 25}

from the statistical studies of Epstein [9], Gifford [ro], and Mikesell [ri] to a much more direct and precise method developed by Barnhart, Protheroe and Galli [12].

Keller [8] has developed a theory which, from the known statistical properties of stellar shadow patterns, summarizes what can be said about the statistical properties of the turbulence which produces them. Protheroe [2] is working on a technique which should develop automatically the auto-correlation function of the shadow-band pattern using the scintillation outputs of two small telescopes with variable centre-to-centre spacing.

The results of optical studies of atmospheric turbulence conducted at the Lowell Observatory under A. G. Wilson's direction are given in another final report [13] which summarizes the results of measures of the scintillation of double stars, balloon-borne light sources and excursion studies with camera and orthicon intensifier.

Using a telescope with a 4 -inch circular aperture Mikesell has found very pronounced changes in scintillation with azimuth. These have been observed at altitudes from $10^{\circ}$ to $70^{\circ}$ at frequencies of 25 c.p.s. and greater.

\section{RADIO-STAR SCINTILLATION}

Booker [14] has made a theoretical discussion of the irregularities in electron density which are responsible for incoherent scattering of radio waves in the ionosphere. He finds that radio-star scintillation can be explained in terms of turbulence at a level of $200-300 \mathrm{~km}$.

An extensive observational study of the spectrum of radio-star scintillation has been made by Wild and Roberts [r5]. They find that most of the fluctuations are probably due to single lens-like irregularities. They have evidence of dispersion in the scintillation patterns, different frequencies being focused at different points on the ground. Diurnal changes in the degree of fluctuation were observed, together with annual changes in the size, shape and motion of the pattern on the ground.

\section{AGE N DA}

Aside from reports on the latest ground-based work on seeing and scintillation, results obtained from manned or unmanned balloons will be of particular interest. A preliminary report of the experiments of Blackwell, Dewhirst and Dollfus has already been published [16].

It is suggested that any matters, which might arise, pertinent to definitions or jurisdiction be deferred to near the end of the single session assigned to Sub-Commission $25 b$.

$$
\begin{gathered}
\text { J. S. HALI } \\
\text { President of the Sub-Commission }
\end{gathered}
$$

\section{REFERENCES}

[I] Rösch, J. Symposium on Astronomical Optics and Related Subjects. University of Manchester. Edited by $Z$. Kopal. 1956. Although this symposium was held before the I955 I.A.U. meeting, and will not be summarized here, the attention of the reader is called to other interesting articles on scintillation and seeing in the same volume.

[2] Personal communication, I957.

[3] Vistas in Astronomy, vol. I, 473, I955.

[4] Ibid. vol. I, 372, 1955 .

[5] Rösch, J. C.R. 244, 3027, I957.

[6] Morphological Astronomy by F. Zwicky, Springer Verlag, 242-8, 1957.

[7] Astr. J. 62, I39, I957.

[8] Keller, G., Protheroe, W. M., Barnhart, P. E. and Galli, J. 'Investigations of Stellar Scintillation and the Behavior of Telescopic Images.' Electronics Research Directorate, Air Force Cambridge Research Center, Air Research and Development Command, Hanscom Field, Bedford, Mass. Final report under Contract no. AF 19 (604)I409, 1956 . 


\section{PHOTOMETRIE STELLAIRE}

[9] Epstein, E. S. Thesis: Penn. State University, June 1955.

[10] Gifford, F. Jr. Bull. Amer. Met. Soc. 36, 35, I955.

[II] Mikesell, A. H. Publ. U.S. Nav. Obs., 2nd ser., 17, I39, I955.

[12] Barnhart, P. E., Protheroe, W. M. and Galli, J. J. Opt. Soc. Amer. 46, 904, I956.

[13] Gardiner, A. J., Gifford, F. Jr., Mitchell, R. I., Giclas, H. L., Johnson, H. L. and Wilson, A. G. 'Optical studies of Atmospheric Turbulence'. Geophysics Research Directorate, Air Force Cambridge Research Center, Air Research and Development Command, Hanscom Field, Bedford, Mass. Final report under Contract no. AF I9 (604)-953, I956.

[14] Booker, H. G. J. Geophys. Res. 6r, 673, 1956.

[15] Wild, J. P. and Roberts, J. H. J. Atmos. Terr. Phys. 8, 55, 1956.

[16] Blackwell, D. E., Dewhirst, D. W. and Dollfus, A. Observatory, 77, 20, 1957 and Nature, Lond., I80, 21 I, 1957.

\section{Report of Meetings. I4, I6 and I9 August I958}

Presidents: R. H. Stoy and W. Becker.

SECRETARY: H. F. Weaver.

Because of the request from the Executive Committee for conciseness, the accounts of the supplementary correspondence between members of the Commission and of the meetings of Commissions 25 and $25 a$ in Moscow have been merged and arranged according to subject.

\section{ORGA N ISATION}

As the scope of Commissions 25 and $25 a$ had now become so similar, it was decided to hold all meetings jointly and to recommend that these commissions be combined. It was also decided to recommend that Commission $25^{b}$ (Qualité des Images) should be renumbered $9 b$ since its subject-matter was more nearly akin to that of Commission 9 (Instruments).

\section{RED AND INFRA-RED MAGNITUDES}

There appeared to be general agreement that there were sound astrophysical reasons, especially in the case of late-type stars, for a photometry to the red of the $U, B, V$ system. It was felt, however, that it was still too early to attempt to lay down any 'official' standards for such a photometry partly because knowledge of the best wave-length ranges is incomplete and partly because observational technique might soon be radically altered by the introduction of new photo-surfaces now being developed.

For red photometry a spectral region centred round $6500 \AA$ was suggested. For an infra-red system the desiderata drawn up by a group of American astronomers in 1956 still appear to be valid, namely

(I) It should have an equal interval in $\mathrm{I} / \lambda$ with the $U, B, V$ spectral regions and about the same equivalent band-width.

(2) One spectral region should be enough.

(3) A sensitivity region affected seriously by variations in cathode sensitivity among cathodes of different photo-cells or photo-multipliers should be avoided.

(4) $\mathrm{H} \alpha$ and the terrestrial water vapour bands, especially the $\rho, \sigma, \tau$ bands at $9300 \AA$ should be avoided.

(5) For efficiency the band-width must be sufficient for the limiting magnitude to correspond as closely as possible to those for the measures made in the $U, B, V$ regions.

(6) It is desirable that the system should be photographically reproducible.

It appears therefore, that the sensitivity band should extend from just to the red of $\mathrm{H} \alpha$ to about $9000 \AA$. The $I$ magnitudes of Kron and Smith [r] and Kron, White and Gascoigne [2] satisfy these requirements fairly well and have been carefully standardized. 


\section{COMMISSION 25}

According to Kron, the exact wave-length band used for the observations of infra-red magnitudes is not critical, as observations made in different wave-bands are fairly easily convertible. For photo-electric observations a cell having a $\mathrm{CsO}$-Ag surface may be used. The sensitivities of such surfaces differ greatly from one another, particularly at the longer wave-length end where the cut-off may be as long as I2,000 $\AA$ or as short as I0,500 $\AA$. In the first case a filter consisting of $2 \mathrm{~mm}$ Schott RG 8 plus $2 \mathrm{~mm}$ Schott BG 2I will be required, while in the second case a filter of $2 \mathrm{~mm}$ Schott RG 8 will be sufficient. Photographically the system can be reproduced by using a Kodak I N plate with a Schott RG 5 filter.

\section{THE $P, V$ SYSTEM OF PHOTOMETRY}

As a nearer approximation to the original 1922 'International' system of magnitudes and as an alternative to $B$ and $V$, several observers are using the $P, V$ system. This $V$ is very close to that of Johnson and Morgan [3] and of Eggen [4], though for refined conversions comparisons can, and must be, made. The zero-point is defined by adjusting the mean of the $V$ magnitudes of the following stars of the North Polar Sequence to the mean of the I922 $I P v$ magnitudes:

$\begin{array}{rrrrr}\text { N.P.S. } 1 & \text { N.P.S. } 6 & \text { N.P.S. } 16 & \text { N.P.S. } 6 \mathrm{r} & \text { N.P.S. 4s } \\ \mathbf{2} & 7 & 19 & 7 \mathrm{r} & 6 \mathrm{~s} \\ \mathbf{3} & 8 & 3 \mathrm{r} & 8 \mathrm{r} & \\ \mathbf{4} & 10 & 4 \mathrm{r} & \mathbf{2 s} & \\ \mathbf{5} & 13 & 5 \mathrm{r} & 3 \mathrm{~s} & \end{array}$

Because of the elimination of light with wave-length shorter than $3800 \AA$, the $P$ magnitudes cannot be adjusted precisely to $I P g$ without a non-linear transformation. $P$ is therefore defined through the linear compromise fit given by Eggen [x]. $P-V$ colours can be compared directly with $I C I$ with systematic errors which are in general less than 0.08 magnitudes. Appropriate filters for use in front of a Cs-Sb photo-surface for reproducing the $P, V$ system are I mm Schott BG I2 plus $2 \mathrm{~mm}$ Schott GG I3 for $P$ and $2 \mathrm{~mm}$ Schott GG I4 for $V$. If a CsO-Ag surface is used, the filters required are $2 \mathrm{~mm}$ Schott BG 23 plus $2 \mathrm{~mm}$ Schott WG I plus I $\mathrm{mm}$ Schott BG I2 for $P$ and $2 \mathrm{~mm}$ Schott GG II plus $2 \mathrm{~mm}$ Schott BG I 8 for $V$.

Complete functional stellar standards for the $P, V, I$ system of photometry are being prepared for publication by Kron and Mayall.

\section{OTHER COLOUR SYSTEMS}

Becker expressed what appeared to be the general feeling that the time had not yet come to define standards for the $R, G, U$ system as further experimentation is still needed.

Roman recommended that the $U, B, V$ three-colour photometry should not be confined to early type stars. The extra $U$ colour was useful for $\mathrm{F}, \mathrm{G}, \mathrm{K}$ stars as a criterion for sorting them out according to population type.

Kron remarked that his regard for the sanctity of photometric systems was not as high as that of many of his colleagues. He thought that all observers must take the commonly-used precautions for dealing with the Balmer absorption effect but, apart from this, he did not see any need for a high degree of standardization of photo-cells, filters or photometric systems. He considered that good $V$ magnitudes can be derived from practically any yellow sensitive plate or photo-cell employing a 'yellow' filter, and that these magnitudes can be transformed into any other magnitude system within the accuracy permitted by the properties of the stars themselves. He maintained that the chief responsibility of the observer is not so much the reduction of his results to someone else's standard system, as the provision of really adequate observations of standards, so that transformations can be made to the systems of other observers when and if they are needed. 


\section{PHOTOMETRIE STELLAIRE}

\section{THE USE OF SCHMIDT TELESCOPES FOR PHOTOMETRY}

Haffner called attention to three investigations [5, 6, 7] carried out with the Hamburg Schmidts. His conclusion is that the individual and systematic errors of magnitudes measured on Schmidt plates can be kept small provided that the optical and mechanical parts of the instrument are in good adjustment. Allowance must be made for certain distance corrections depending amongst other things on the difference between the optical and emulsion surfaces. On the other hand, the Schmidt does not seem to be a suitable instrument for transferring magnitude sequences.

Stock, from his experience at Cleveland and Hamburg, confirmed Haffner's remarks. He stressed the importance of the proper adjustment of the optical components, particularly of the proper alignment of the correcting plate and mirror. The tilt of the plate holder is more difficult to adjust but the errors caused by any maladjustment have a definite form and can be relatively easily determined. A more serious problem is caused by non-uniform sensitivity of the emulsion across the plate. This can only be eliminated by averaging the results from several plates. In the particular case in which it is required to transfer magnitudes from one small area of a plate to another small area of the same plate, the errors can be greatly reduced by pointing the telescope midway between the two areas and taking two equal exposures, one of them being with the telescope reversed.

Redman too stressed the necessity for great mechanical rigidity in the mounting of the optical components and the need for uniform reflectivity over the mirror surface. He also pointed out that photometric measures of photographic images on Schmidt plates can be expected to show greater random errors than are usual for refractor images since they will contain relatively fewer grains because of the higher efficiency of the Schmidt optical system.

Redman gave some numerical results based on Argue's work with the Cambridge Schmidt. Measures made with an iris-diaphragm photometer on six 'blue' plates with 30-minute exposures indicated that the probable error of a measure of a single image ranged from \pm 0.017 magnitude at magnitude 7 to \pm 0.036 at magnitude 13 and \pm 0.074 at magnitude $I_{5}$. Field errors appeared to be negligible out to $I_{2}^{1}$ radius where vignetting begins. Malfocusing led to systematic errors varying approximately as $(\Delta f)^{2}$. For $\Delta f=0.025 \mathrm{~mm}, \Delta m=0.018$ magnitude in the blue and 0.008 in the red. Due to variations in seeing and guiding, transfers of scales or zero-points from field to field were not very reliable.

With reference to the speed with which plates could be measured with an iris-diaphragm photometer, Redman said that it took two people, the one measuring, the other recording, 8 hours to measure I000 star images in a crowded star field which required the use of an identification chart. It took a further four man-hours to punch the readings together with the magnitudes and colour indices of the standard stars on to paper tape, while the final reduction to magnitudes for these rooo stars took only 5 minutes on the EDSAC II computer at the Cambridge Mathematical Laboratory.

\section{RECENT IMPROVEMENTS IN PHOTO-ELECTRIC TECHNIQUE}

Baum described some experiments that had been made at Mount Wilson with one of the new R.C.A. C 7237 end-on multi-alkali I4 stage photo-multipliers. The spectral sensitivity is wider than that of the $\mathrm{Sb}-\mathrm{Cs}$ cathodes now in general use, including their range and extending it to the red by a further I500 $\AA$. It is thus possible to measure $U, B, V$ and $R$ magnitudes with the same cell, but the exact reproduction of the $U, B, V$ response functions is difficult since these depend on the spectral sensitivity curve of the Sb-Cs cathode. The new cell appears to be more sensitive than the I P 2I and its dark current is less. Refrigeration appears to improve the behaviour of the cell which, so far, has not been used to make any actual stellar observations.

A pulse-counting photometer that had recently been brought into use at the McDonald Observatory was described by Hiltner. It employs six cells and dichroic filters and simultaneously measures sky and star plus sky in three colours. 


\section{ATMOSPHERIC EXTINCTION}

At the joint meeting of Commissions $12,13,25,27$ and 36 Nikonov gave a short talk in which he stressed the need for a 'Standard Catalogue of Extinction Stars'. He pointed out that at many observatories the atmospheric extinction varies irregularly with time and that at any given time it may be different in different azimuths. This makes such wellknown methods of determining the extinction as Bouger's meaningless. If, however, the sky were covered with a sufficiently extensive network of stars with known extraterrestrial magnitudes and colours it would be possible to determine the coefficients of extinction at the particular time and the particular part of the sky under consideration. The fundamental catalogue planned by the Crimean and Cracow Observatories along the lines suggested by Rybka [8] may be considered as an attempt to provide such a catalogue. It is to be on the $U, B, V$ system and to include two stars of approximately magnitude 6 and of spectral type $A$ and $K$ in each of the northern Kapteyn Areas. The catalogue could be enlarged to include also pairs of stars of magnitude 8 and Io. Nikonov concluded with the interesting suggestion that it might be possible to use the brightest stars for a study of the extinction during daytime.

\section{GENERAL CATALOGUE OF MAGNITUDES}

Before making any further recommendations about the adoption of standard magnitude systems, zero-point stars, etc., the Commission considered that it was desirable to prepare a comprehensive review of the material already available and to consolidate it as far as possible into a homogeneous scheme. It therefore recommended that a General Catalogue of Magnitudes should be prepared. This recommendation grew out of an initial suggestion from Rybka combined with a general feeling within the Commission which was perhaps most clearly expressed by Eggen

I believe that the attempt to set up magnitude sequences on a well defined system in all parts of the sky that might be suggested, and to a magnitude limit that would satisfy all concerned, is a wasteful and not particularly desirable activity for Commission $25 \ldots$

It seems to me that most large-scale photometric investigations in the future will be done by photographic interpolations from photo-electric sequences... Therefore, it seems to me what is basically required is a network of 'zero-point' and 'colour equation ' stars conveniently distributed.

It was proposed that the new catalogue should consist of three sections. The first section is to be restricted to well observed stars for which it is possible to deduce $V$ magnitudes and $B-V$ or $P-V$ colours with external standard errors of 0.0 I magnitude or less. It is anticipated that this section, which will define the system of the whole catalogue, will contain several hundred stars including many bright stars, many nearby stars, stars in well observed standard areas and open clusters etc., but multiple stars and stars with companions within $2^{\prime}$ of them will be omitted. The system of the catalogue will be close to the existing $V, B-V$ and $P-V$ systems of which it is intended to be a rationalization.

The second section of the catalogue is to contain all those stars for which reliable magnitudes and colours have been determined and which can be linked with the system of the first section so that the standard error of the resulting magnitude and colour is 0.02 magnitude or less. There will probably be several thousand stars in this section. As far as possible all other relevant information, for example, spectral types, $U-B, R-I$ colours, etc., will be included for the stars in the first two sections of the catalogue. Later Bidleman proposed that the second section should be somewhat extended to make it complete for those stars for which a modern spectral type has been determined on the $M K K$ or related systems.

The third section of the catalogue is to list all the major catalogues and other sources of 


\section{PHOTOMETRIE STELLAIRE}

magnitudes and attempt to indicate the reliability of the magnitudes contained therein and their relationship to the adopted standard magnitude system.

It was proposed that the catalogue as a whole should try to include all magnitudes available before I959 December 31, but it was contemplated that work on it should begin almost immediately. For an undertaking of this size, cooperation was regarded as essential. Nikonov, Parenago, Rybka and Stoy indicated that they were willing to take an active part in the project.

In a preliminary discussion, Rybka outlined his researches into the systematic corrections required by the various Harvard visual catalogues. He pointed out that it had only recently become possible with the availability of photo-electric magnitudes and colours for a large number of bright stars fully to determine these systematic corrections and he thought that it should be possible to prepare a reliable catalogue of visual magnitudes complete to magnitude 7.5 from the Harvard and Potsdam photometries within three years.

Blanco reported that a systematic comparison of the Harvard and Potsdam visual magnitudes with the photo-electrically determined magnitudes on the Johnson-Morgan system had also been made at the Case Institute. About 800 stars from each catalogue had been investigated and, apart from the usual colour corrections, scale and zero point errors, effects depending on declination, right ascension and background had been found. The probable error of a Harvard and Potsdam magnitude after reduction to the $V$ system was \pm 0.02 magnitude.

Stoy remarked that some years ago, Knox-Shaw had re-examined the southern Harvard visual magnitudes, applied systematic corrections to the individual series and combined them into a fairly homogeneous catalogue. Typescript copies of this catalogue were available at the Radcliffe and Cape Observatories. Work such as this and such as Ryblka and Blanco had described should be very useful in the compilation of the third section of the proposed catalogue.

\section{POLARIZATION}

It was generally agreed that the polarization of star light came naturally into the scope of Commission 25. Hall announced that a catalogue giving the polarization of approximately 2500 stars down to magnitude I4 would shortly be published and might be sufficient to meet Wesselink's request for a number of stars of known polarization to help in the calibration of observations made at the Newtonian focus of a reflector. Hall also drew attention to the fact that the light of most faint stars was polarized and that this should be taken into account when setting up magnitude sequences for faint stars.

\section{REFERENCES}

[1] Kron, G. E. and Smith, J. L. Ap. J.113, 324, 1951.

[2] Kron, G. E., White, H. S. and Gascoigne, S. C. B. Ap. J. 118, 502, 1953.

[3] Johnson, H. L. and Morgan, W. W. Ap.J. I17, 313, 1957.

[4] Eggen, O. J. Astr. J. 60, 65, 1955 .

[5] Heckmann, O. and Lübeck, K. Z. Ap. 40, I, I956.

[6] Heckmann, O. and Lübeck, K. Z. Ap. 45, 243, $195^{8}$.

[7] Haffner, H. Mitt. Astr. Ges. I955, 44, I956.

[8] Rybka, E. Vistas in Astronomy, I I I I, 1956. 


\section{COMMISSION 25}

\section{Compte rendu de la Séance de la Sous-Commission 25b. I8 août I958}

PrÉsident: J. S. Hall.

SECRÉTAIRE: J. Rösch.

Le Président signale que la transformation de la Sous-Commission $25 b$ en une SousCommission de la Commission 9 (Instruments) a été discutée et reconnue opportune aussi bien par les membres de la Commission 9 que par ceux de la Commission 25 lors de leurs réunions pleinières. En conséquence, les Présidents de ces deux Commissions ont soumis au Comité Exécutif des propositions de résolution dans ce sens.

Le Président attire l'attention sur la nécessité d'une terminologie correspondant aux différents aspects des phénomènes observés. Le terme seeing n'ayant pas toujours pris la même valeur pour tous les auteurs, il est recommandé d'employer l'expression 'qualité des images', ou ses traductions littérales, pour l'ensemble de la question considérée, et les termes d'étalement (blurring, ou smearing, en anglais), d'agitation (agitation ou dancing), et de scintillation (scintillation, ou twinkling) pour les divers types de détérioration rencontrés.

L'ordre du jour appelle un certain nombre de communications sur des travaux réalisée depuis la IXe Assemblée Générale.

J. L. Steinberg rend compte des observations faites avec I. Kazes sur les fluctuations du rayonnement des sources solaires sur $3 \mathrm{~cm}$ de longueur d'onde, au voisinage de l'horizon, en utilisant une ou plusieurs antennes. Ces scintillations sont d'origine atmosphérique et dépendent de la hauteur de l'astre de la même façon qu'en optique. Les ombres portées ont un rayon de corrélation de $200 \mathrm{~m}$ environ et se déplacent sur le sol avec des vitesses voisines de celle des vents au niveau de la tropopause.

$\mathrm{J}$. Arsac expose les grandes lignes d'une théorie de la scintillation en ondes centimétriques, utilisant des développements limités au Ier ordre, mais tenant compte de la totalité des inhomogénéités de l'atmosphère. Avec des hypothèses simplificatrices telles que: isotropie des inhomogénéités et invariance de leurs propriétés avec l'altitude, il semble qu'on ne puisse remonter des scintillations observées en ondes centimétriques aux propriétés statistiques de l'atmosphère.

G. Keller fait remarquer l'importance des résultats de Steinberg, Kazes et Arsac dans le domaine de la scintillation radio-électrique, qui peut seule donner des renseignements sur les éléments turbulents mesurant des dizaines ou centaines de mètres, tandis que la scintillation optique ne peut fournir de données que sur les éléments de quelques décimètres.

Mlle Bugoslavskaya relate des expériences sur les trainées d'étoiles faites à Moscou au moyen d'un astrographe couvrant $6^{\circ} \times 6^{\circ}$. L'instrument est immobile. On constate que deux trainées d'étoiles distantes de $I^{\circ}$ cessent de se ressembler. Les trainées présentent des condensations à intervalles réguliers de $0 \cdot 3$ seconde, que l'auteur explique par la scintillation.

V. P. Linnik expose une méthode d'étude de la surface d'onde sur l'objectif consistant à disposer après le foyer de l'instrument un biprisme donnant des images virtuelles superposées de deux moitiés de l'objectif; l'œil placé à la suite aperçoit des franges d'interférences localisées sur la partie commune à ces deux images. Ces franges seraient rectilignes s'il n'y avait pas de turbulence; en fait leur déformation traduit celle de la surface d'onde. La méthode présente l'avantage de ne nécessiter aucun réglage, et de ne faire perdre que très peu de lumière. L'auteur estime pouvoir photographier en $\mathrm{I} / 25^{\circ} \mathrm{de}$ seconde sur plaques de sensibilité 200 Weston les franges fournies par une étoile de magnitude zéro.

W. M. Protheroe rend compte des travaux du groupe de l'Université de Pennsylvanie. On reçoit une image d'étoile formée par un objectif de $10 \mathrm{~cm}$ de diamètre sur un photomultiplicateur dont on analyse le courant de sortie par des filtres isolant les fréquences I $2 \mathrm{c} / \mathrm{s}$ et $300 \mathrm{c} / \mathrm{s}$. On définit un 'module de scintillation' dont on étudie la corrélation avec le vent en altitude. On trouve un coefficient de corrélation de $0 \cdot 9 \mathrm{I}$, et une concordance à 


\section{PHOTOMETRIE STELLAIRE}

$\pm 5 \mathrm{~m} / \mathrm{sec}$ près entre la vitesse de vent ainsi évaluée et celle fournie par les sondages météorologiques. En diaphragmant l'objectif par une fente de $4 \times \mathrm{r} \mathrm{cm}$, on trouve un minimum de scintillation sur $300 \mathrm{c} / \mathrm{s}$ pour certaines orientations de la fente. Le coefficient de corrélation avec la direction de vent déterminée par les sondages est de 0.96 , et la direction trouvée par la scintillation concorde à $\pm \mathrm{I} 3^{\circ}$ près avec celle des sondages. Les expériences ont été reprises en se référant aux sondages faits par ballons suivis au radar.

G. Keller décrit ses expériences sur les ombres volantes. Le dispositif employé consiste en deux lunettes de $25 \mathrm{~mm}$ de diamètre ayant leurs axes parallèles dans un plan orientable, la distance entre les axes étant également réglable. Le domaine spectral utilisé s'étend de 0.43 à $0.50 \mu$. Les courants photo-électriques fournis par les deux lunettes sont comparés par un système électronique (réalisé par Protheroe et Barnhardt) qui fournit directement le coefficient de corrélation en fonction de la distance des axes. Quand le plan des axes est parallèle à la direction du vent au niveau de la tropopause, on constate un minimum négatif prononcé pour une distance de l'ordre de $10 \mathrm{~cm}$, minimum qui est très atténué dans le cas d'une orientation perpendiculaire à la direction du vent. On a introduit sur l'un des deux circuits une ligne à retard pour déterminer le temps de déplacement des fluctuations d'un objectif à l'autre.

W. M. Protheroe ajoute à la communication de G. Keller la description d'un analyseur optique qui sera monté sur le télescope de 28 pouces de l'Observatoire Flower-Cook. On forme une image de l'objectif sur un réseau de Ronchi ou un réseau à transmission sinusoïdale. Le courant photo-électrique obtenu après traversée du réseau est proportionnel à la composante de Fourrier de fréquence spatiale correspondant à celle du réseau dans la répartition de l'énergie sur l'objectif.

J. Rösch expose une méthode devant permettre de sélectionner, pour une photographie d'étoile à très courte pose (notamment au moyen de la camera électronique de Lallemand) les instants où la définition est la meilleure. Si l'on forme sur une fente, par un dispositif approprié, une série d'images données par des portions circulaires de l'objectif de l'ordre de 15 à $20 \mathrm{~cm}$, chacune de ces images est peu différente de l'image de diffraction théorique et l'on peut choisir une largeur de fente ( 0.6 fois le rayon du premier anneau sombre) donnant la plus grande variation de flux transmis en fonction de la distance centre de l'image - axe de la fente. Le flux recueilli après la fente sur laquelle se forment toutes les images élémentaires est maximum lorsque la surface d'onde est plane sur toute l'étendue de l'objectif. Une expérience photographique a permis de montrer que ce dispositif éliminerait pratiquement toutes les images diffuses.

Mme Demidova décrit des expériences montrant que la scintillation peut être représentée en fonction de la distance zénithale $z$ par une expression de la forme $A=A_{0}(\sec z)^{\alpha}$. Avec $200 \mathrm{~mm}$ d'ouverture on a trouvé, à Poulkovo et à Anapa respectivement, $A=44 \%$, et $52 \%$, et $\alpha=\mathrm{I} \cdot 3$ et 0.9 . Avec une ouverture de $30 \mathrm{~mm}$, à Poulkovo, on a trouvé $A=\mathrm{I} 27 \%$ et $\alpha=\mathrm{I} \cdot \mathrm{O}$. Les résultats de Protheroe sont confirmés, ainsi que la concordance avec la qualité des images estimée par la méthode de Danjon.

Mme Bistrova a étudié la corrélation entre les déplacements de deux images d'une même étoile, obtenues en couvrant par des prismes de petit angle deux trous de $6 \mathrm{~cm}$ dont les centres sont distants de $\mathrm{I}_{4} \mathrm{~cm}$, à l'entrée d'un télescope Maksutov de $20 \mathrm{~cm}$ de diamètre et Io $\mathrm{m}$ de longueur focale. En 22 nuits, on a trouvé un déplacement relatif moyen des deux images l'une par rapport à l'autre de 0.35 . Les résultats sont en bon accord avec les estimations de qualité par la méthode de Danjon, ainsi qu'avec ceux de Strömgren sur les photographies d'étoiles doubles.

Koltschinsky, à Kiev, a également enregistré des trainées d'étoiles, mais au moyen d'un astrographe de $400 \mathrm{~mm}$ de diamètre et $5.5 \mathrm{~m}$ de longueur focale. Il trouve une variation de l'agitation de la forme $\Delta=0^{\prime \prime} 35 L^{0.47}, L$ étant la masse d'air traversée. Les périodes trouvées pour les déplacements sont comprises entre I et 6 secondes; mais on a enregistré des déplacements de périodes $0 \cdot 1$ et $0 \cdot 2$ secondes sur une plaque animée d'une vitesse de translation de 5 à ro millimètres par seconde.

Le dernier point de l'ordre du jour concerne la coordination des études sur les emplacements d'observatoires. 


\section{COMMISSION 25}

A ce propos, I. Kutcherov rend compte des recherches faites en U.R.S.S. sur l'astroclimat de 4 stations différentes, au moyen de télescopes de $20 \mathrm{~cm}$ de diamètre et ro $\mathrm{m}$ de longueur focale. Il insiste sur la nécessité d'une co-opération internationale en vue de définer les liens entre les données atmosphériques et géographiques et les qualités d'un emplacement, et de faire apparaître ainsi à l'échelle mondiale les sites les plus appropriés pour l'édification de nouveaux observatoires.

Sur cette même question, $\mathrm{P}$. Bourgeois rappelle la résolution soumise à l'Assemblée Générale par la Comité Belge d'Astronomie, émettant le vœu que l'U.A.I. organise dès que possible un Symposium sur les problèmes de recherche des sites d'observatoires.

Après discussion, il est décidé de soumettre au Comité Exécutif de l'Union la recommandation suivante (résolution no. r9):

La Sous-Commission $25 b$ recommande que le vœu du Comité Belge d'Astronomie (point I 3 c de l'ordre du jour de l'Assemblée Générale) soit pris en considération, et qu'un Symposium sur les problèmes de recherche de sites d'observatoires soit organisé par l'Union Astronomique Internationale dès que possible. 